\title{
The PLC Control of Six-Axis Manipulator Based on S7-200
}

\author{
Guodong Zhang ${ }^{a}$, Ruimin $Q i^{b}$
}
College of Mechanical and Electrical Engineering, Zhengzhou University of Industrial Technology, Zhengzhou, China
azhangguodong1983@126.com, 'brm2007@126.com

Keywords: PLC; six-axis manipulator; host computer

\begin{abstract}
In order to improve the automation of industrial production and production efficiency. This paper presented a system with the S7-200 as the core. The system adopted the method of sequence control. The S7-200 mainly controlled the step motor, dc motor, servo motor, Through the control could realize manipulator grasping object, walk, put down, The PC could monitor the process, and the PC could track, detecting objects. So, the system can realize intelligent.
\end{abstract}

\section{Introduction}

Six axis manipulator is a new type of device, it can be applied to industry, agriculture and national defense. It can replace human repetition, heavy manual work, It can work in the dangerous environment. The robots can imitate human's arm, and can grab objects, handling object, placed object. Six axis manipulator mainly includes: the base, I joint, II joint, III joint, IV joint, V joint, VI joint, gas to grasp, As shown in figure.1.

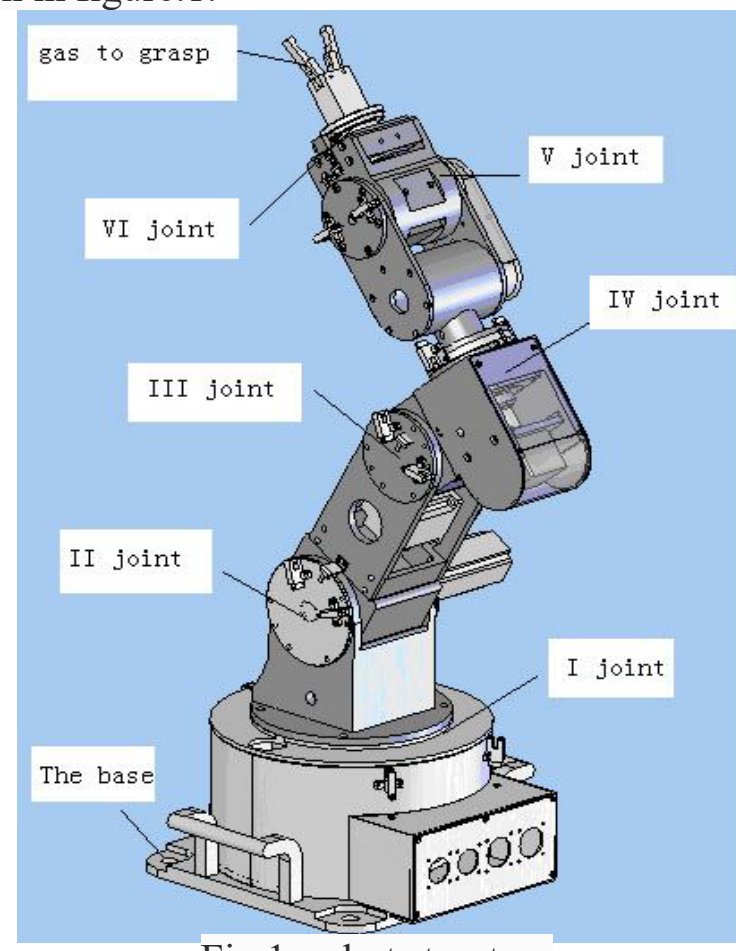

Fig.1. robot structure

By the structural diagram you can see, drive, drive mode of each joint, I joints is step-motor direct harmonic reducer; II joints is servo motor directly connected harmonic reducer; III joints is stepping motor through the synchronous belt wheel harmonic reducer; IV joints is step-motor direct harmonic reducer; $\mathrm{V}$ joints is stepping motor through the synchronous belt wheel harmonic reducer; VI joints is step-motor direct harmonic reducer; Each joint are equipped with photoelectric limit switch plus or minus two direction and two directions hard limit switch. In terms of overall structure, the manipulator is not complicated, The key lies in the parameter matching, because the tandem structure features in the process of the movement is that the torque of each joint is to change all the time. Overall coordination and stiffness are more demanding. At the same time for motor 
control, the demand is higher, because the torque changing, require motor moment, control is relatively complex and difficult, so the calculation and analysis is more important. In the design process, the point is to calculate the relevant after purchased components, Actually calculating process is to selection speed reducer and motor

\section{Overall Design}

Manipulator control system of six axis include: an industrial computer; two motion control card; the I/0 module; driver; servo motor. The overall block diagram is shown in figure. 2 .

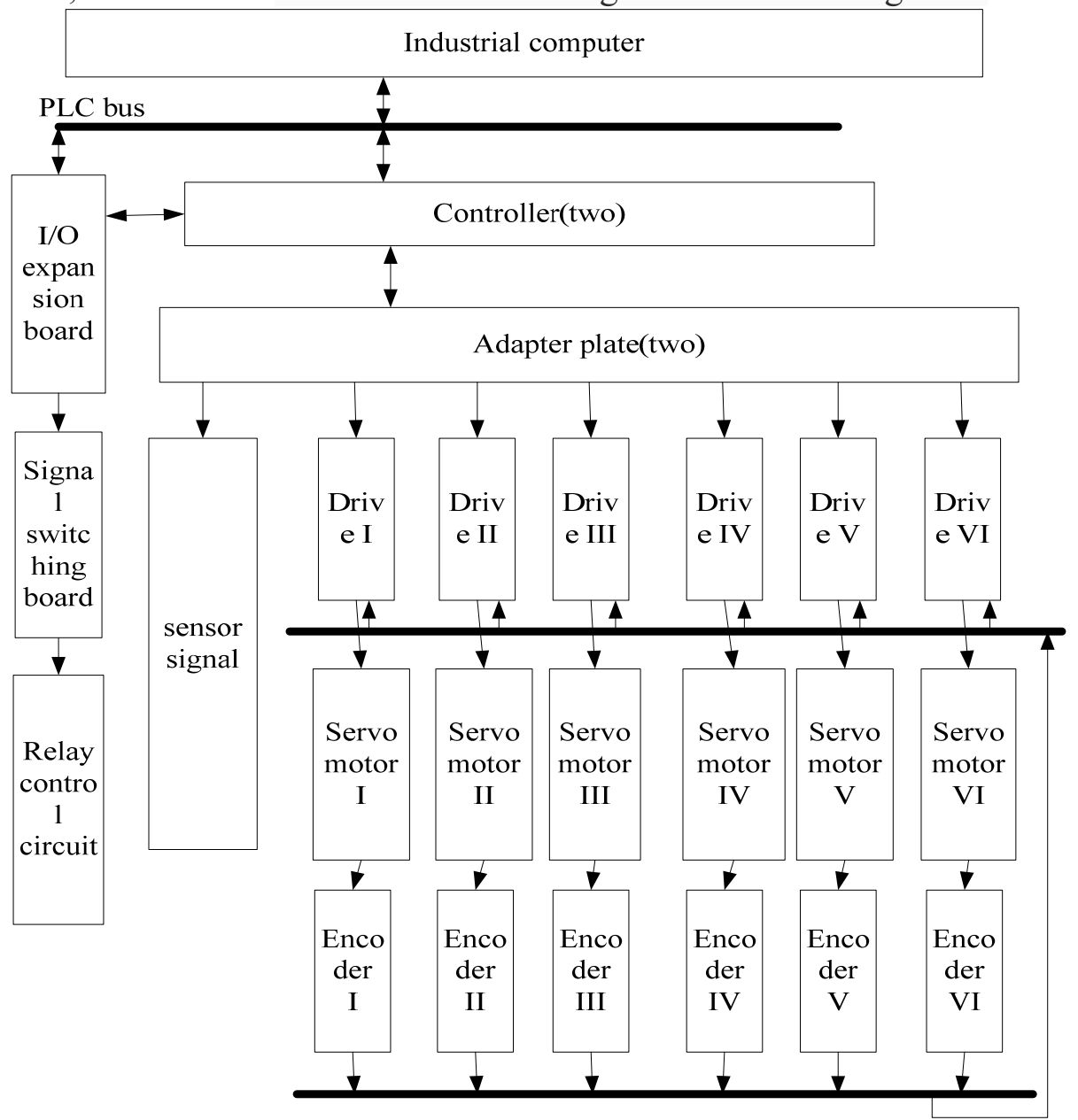

Fig.2. overall block diagram

\section{The Choice of Hardware}

The Choice Of Movement Control CARDS. Motion control card is the core of the system. Usually, the PC connect control card by bus. The PC can monitor the system. Other control CARDS don't have enough anti-interference ability and it have poor stability, So, This design is mainly use the MP2300, it has enough storage capacity, and has good expansibility, the most important thing is that it has a connector. It has anti-jamming capability, the stable performance is good.

The Choice Of Joint Motor And Reducer. How to select the second joint manipulator of the motor? How to choose a reducer? These two problems is very important. Under the experimental conditions, bear the weight of the second joint: $\mathrm{F}=12 \mathrm{Kg}$; The center of gravity offset: $\mathrm{S}=300 \mathrm{~mm}$; Joint range: $\theta=90^{\circ}$; angular velocity: $V=60^{\circ} / \mathrm{s}$; The angular acceleration: $\omega=\pi / 2.25$. So:

The static torque

$$
T_{1}=F \times 9.8 \times S=12 \times 9.8 \times 0.3=36 \mathrm{~N} \cdot \mathrm{m}
$$

The acceleration torque: 


$$
T_{2}=F \times S^{2} \times \omega=1.6 \mathrm{~N} \cdot \mathrm{m}
$$

The total torque:

$$
T=T_{1}+T_{2}=37.6 \mathrm{~N} \cdot \mathrm{m}
$$

The choose: Fuji $100 \mathrm{w}$ servo motor; Harmonic reducer XB1-60-150. Proofreading: output torque of servo motor is about $0.32 \mathrm{~N} \cdot \mathrm{m}$; The motor inertia: $J_{1}=0.054 * 10^{-4} \mathrm{Kg} \cdot \mathrm{m}^{2}$; harmonic reduction ratio: $i=160$; servo motor torque is under $72 \mathrm{~N} \cdot \mathrm{m}$. Servo motor can produce torque though harmonic. The torque is $0.32 * 150=48 \mathrm{~N} \cdot \mathrm{m}$. Safety factor: $48 / 37.6=1.28$. It is greater than 1.2 .

\section{The RV Transmission Principle}

The RV transmission principle as shown in Figure .3, $\mathrm{t}$ includes involute cylindrical gear planetary retarding mechanism and cycloidal planetary reduction mechanism, involute planet gear II becomes an organic whole repeatedly with the crank shaft III, If the center of involute gear 1 clockwise, involute planetary gear in the revolution and counterclockwise rotation.

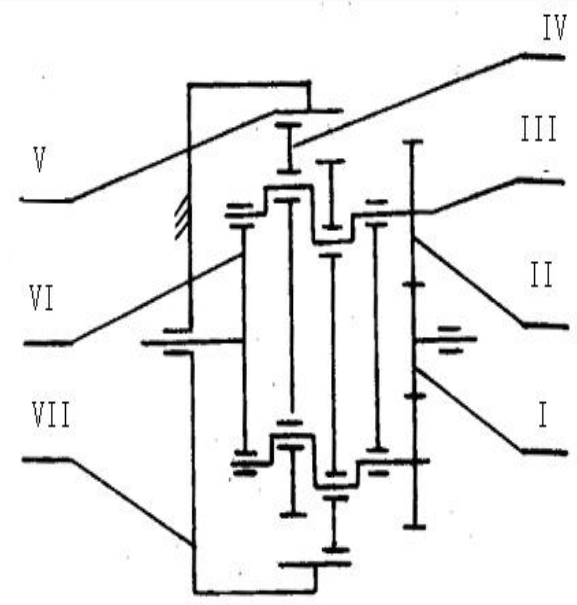

Fig .3. The RV transmission diagram

The RV drive as a new type of drive, from the point of view of structure, its basic characteristics can be summarized as follows: large range of transmission ratio; high transmission efficiency; Stiffness big; Life is long.

\section{The Software Design}

The main purpose of the software design is to determine the state and conditions, As shown in figure.4.first, manipulator is reset, Second, the manipulator I joint turn 90 degrees to the right, II, III, IV, V and VI joints must be in place, Manipulator grasp objects. II, III, IV, V, VI joint go back, the manipulator I joint turn 90 degrees to the left, Robots walk a short distance, Manipulator is opened, Manipulator is reset.

\section{PC Software}

Configuration software is to realize the human-computer interaction, it is a powerful and it can monitor the machine. Monitoring interface as shown in figure.5, by monitoring the picture, you can see the state of the upper machine and lower machine and reset. In order to improve the humanized design, this monitoring purposely increase the button, and it can realize the reset, alarm and online.

\section{Summary}

We realized the control of the manipulator, and we realize the communication between upper machine and lower machine. This system has been used in the experiment. 


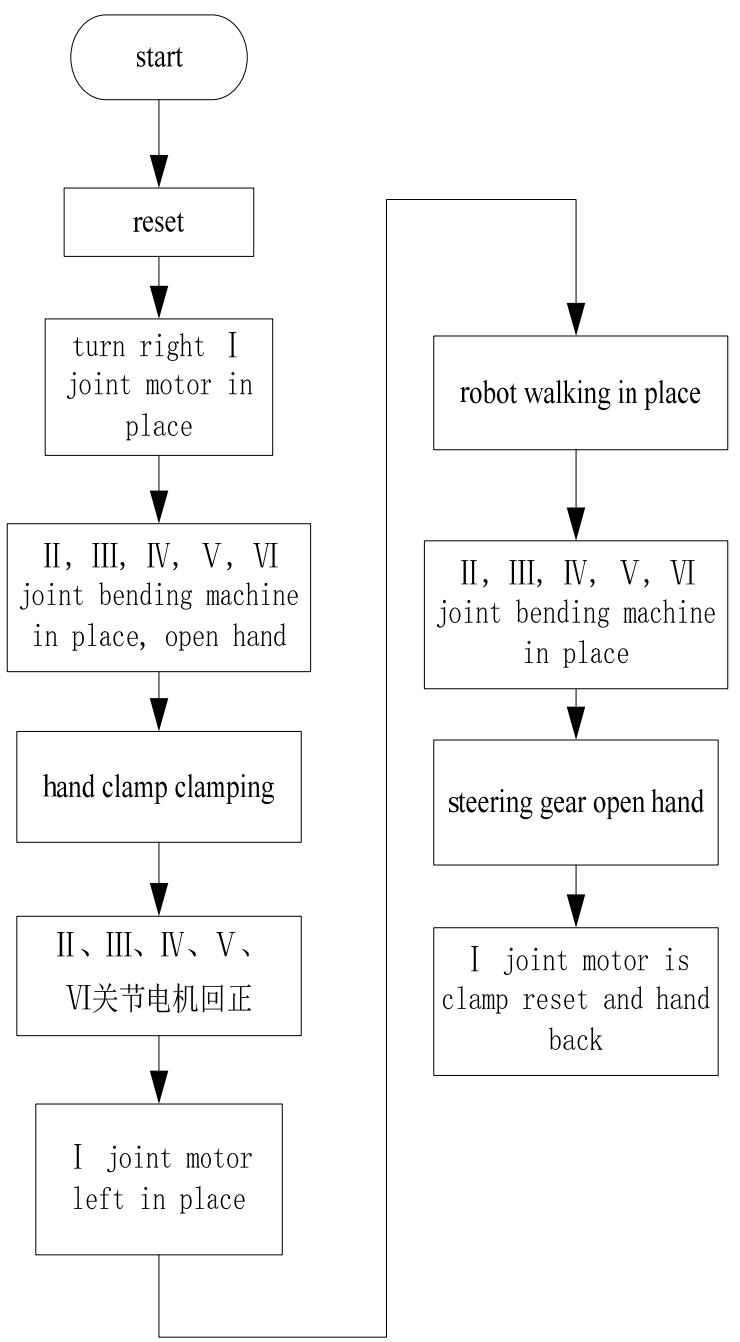

Fig.4. manipulator work flow chart

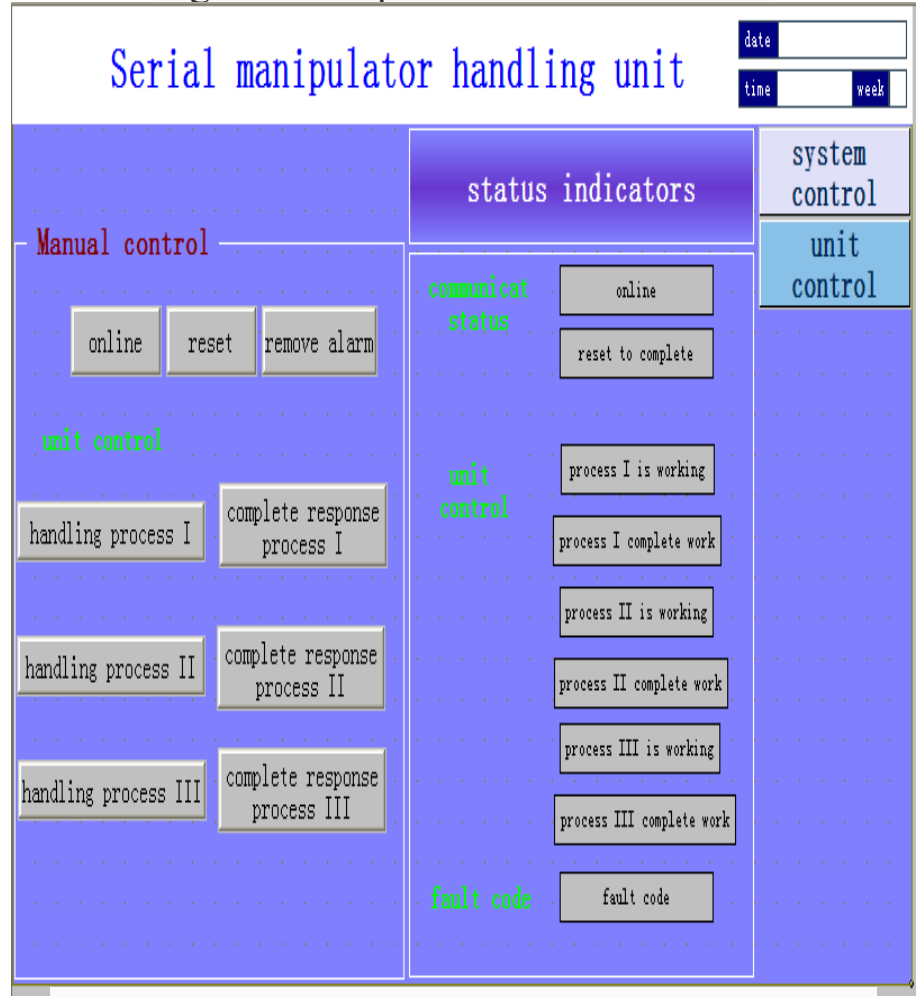

Fig.5. series monitoring figure of the manipulator 


\section{References}

[1] Gui qing Zhao \& peng Chan.2011. Based on the S7-200 control of the manipulator. [J] Coal mine machinery.

[2] Wei ling Huang.2009. The design of the pneumatic carrying manipulator based on PLC[J]. Coal mine machinery.

[3] Ming-liang Wu. 2005. Programmable controller training tutorial[M]. Beijing:Chemical industry press.

[4] Zhi yong Zhang.2008. Research on controlled system of apple picking robot arm[J]. Journal of China agricultural university.

[5] Xiao-dong Wang. 2011. Design method of PLC control system[J]. Automation and instrumentation.

[6] Xiang yang Li \& geng he Luo.2010. The PLC control of the manipulator[J], Journal of xi 'an aviation technology college, 